\title{
Networks of Regulatory Agencies as Regional Public Goods: Improving Infrastructure Performance
}

\author{
By Sanford V. Berg and Jacqueline Horrall ${ }^{1}$ \\ August 30, 2007 \\ Journal article is available at www.springerlink.com.
}

\begin{abstract}
Networks of sectoral regulatory agencies provide regional public goods (RPGs). In developed and developing countries, the telecommunications, energy, and water sectors have been re-structured (frequently liberalized) and reformed over the past two decades. Often with seed money from international organizations and donor countries, regulatory leaders at newly created commissions sought to learn from neighboring countries. Regional networks provided vehicles for sharing data and best-practice techniques, developing studies, providing training, distributing regulatory materials, and organizing meetings. Three properties of publicness of RPGs influence the provision of RPGs: non-rivalry of benefits, non-excludability of non-payers, and the aggregation technology. External donor funding and the mix of characteristics have influenced the pattern of network activities.
\end{abstract}

Keywords: regional public goods, regulatory networks, infrastructure, collective action

\section{Introduction}

Regional networks of regulatory agencies have emerged as important players on the international scene: "These government networks are key features of world order in the 21st century. But they are under-appreciated, under-supported, and under-used to address the central problems of global governance.” (Slaughter, 2004: 159) Recent studies have identified the mix of organizational features characterizing these new networks: they are voluntary, consensus driven, generally lacking in formal treaty status, and (often) focusing on technical issues where cross-nation learning (and tracking) is important. In addition, different types of networks deal with information, enforcement, and harmonization. For example, in the enforcement arena, financial regulators in the securities and insurance industries have collaborated to deal with taxation, codes of conduct, and criminal issues (Slaughter, 2000).

\footnotetext{
${ }^{1}$ Distinguished Service Professor, Economics (University of Florida) and Assistant Professor of Economics, (University of Pittsburgh at Greensburg), respectively. Contact the corresponding author at sberg@ufl.edu. We gratefully acknowledge funding from the Public Utility Research Center (UF) www.purc.ufl.edu; this paper does not necessarily reflect the views of sponsoring organizations. Helpful comments on earlier drafts were provided by journal referees and by Alejo Molinari, Harry Koller, and Jose Tavara. Each author blames the other for remaining errors or inconsistencies.
} 
The contribution of the present paper to the literature is its focus on regulatory networking that has grown in importance over the last decade. Such informational collaborations among professionals at infrastructure regulatory agencies have not been analyzed very thoroughly. The lack of study is surprising, given the hundreds of billions of dollars in public and private investments for energy, telecommunications, and water. Thus, we find new cross-country collaborations among national regulatory commissions that provide oversight, establish investment targets, and/or set prices and quality standards. Professionals from these agencies have tended to focus on information-sharing via a variety of activities.

Between 1990 and 2005, more than 200 regulatory commissions were created around the world (Brown, et al. 2006, p. xi). Thus, the growth of national regulatory commissions is well-documented. For example, Kessides (2004) reports that many countries seeking private participation in infrastructure split off from government ministries the responsibility for implementing policy — providing newly created agencies some insulation from election cycles and a degree of autonomy from elected officials. Jordana and Levi-Faur (2005) provide an analysis of the diffusion of regulatory commissions in Latin America-showing sectoral, cross-country, and national influences. Other regions of the world experienced similar expansions in the number of regulatory agencies.

The growth of regional regulatory networks that provide regional public goods (RPGs) related to infrastructure is not well-documented. ${ }^{2}$ Since 1990, at least 17 associations have been formed to provide a variety of RPGs: data for benchmarking, handbooks on regulatory best-practice, studies (including lessons regarding impacts of different policies), capacitybuilding for professional staff, materials for educating stakeholders, and sponsored meetings. Table 1 lists the RPGs by founding dates ${ }^{3}$, with state and provincial associations for the U.S. and Canada (established in 1889 and 1976, respectively) included since both are active in international collaborations.

\footnotetext{
${ }^{2}$ Regional regulatory networks are comprised of representatives from national regulatory bodies who have agreed to form an association or organization that facilitates collaborative activities. Although few have examined the phenomenon, Eberlein and Grande (2005) describe the role of the Council of European Energy Regulators (CEER) in developing and implementing regional policies. Less attention has been given to the regional networks in emerging markets that tend to arise for information sharing, rather than harmonization. One referee noted that the transactions costs associated with harmonization (owing to lack of autonomy) are higher than those linked with information sharing-leading to greater emphasis on the latter.

${ }^{3}$ The timing of organizational formation can be imprecise: early organizational meetings might only involve some of the countries that ultimately are labeled as founding nations. Thus, we report the date listed on organizational Web sites. In many cases initial funding for a secretariat, for travel, and/or for meetings was provided by multilateral organizations such as the World Bank and by national donor agencies such as USAID. The role of such seed money is discussed in the next section.
} 
Table 1. Founding Dates of Regional Regulatory Networks ${ }^{4}$

\begin{tabular}{|c|c|c|}
\hline Date & Organization & Seed Money \\
\hline 1889 & $\begin{array}{l}\text { NARUC } \\
\text { (National Association of Regulatory Utility } \\
\text { Commissioners) Telecom, Energy, Water-- United } \\
\text { States, Puerto Rico, Virgin Islands }\end{array}$ & \\
\hline 1976 & $\begin{array}{l}\text { CAMPUT } \\
\text { (Canadian Association of Members of Public } \\
\text { Utility Tribunals) Energy Water, Gas, Pipeline } \\
\text { Utilities, Canada and the United States }\end{array}$ & \\
\hline 1995 & $\begin{array}{l}\text { SATRC } \\
\text { (South Asian Telecommunications Regulators’ } \\
\text { Council) }\end{array}$ & ITU \\
\hline 1997 & $\begin{array}{l}\text { IRG } \\
\text { (Independent Regulators Group) Telecom }\end{array}$ & EU (European Union) \\
\hline 1997 & $\begin{array}{l}\text { ARIAE } \\
\text { (Asociación Iberoamericana de Entidades } \\
\text { Reguladoras de la Energía, } \\
\text { Latin-American Association of Regulatory } \\
\text { Agencies for Energy) }\end{array}$ & $\begin{array}{l}\text { Energy Commission of } \\
\text { Spain (CNE) }\end{array}$ \\
\hline 1997 & $\begin{array}{l}\text { TRASA } \\
\text { (Telecommunications Regulators Association of } \\
\text { Southern Africa) }\end{array}$ & $\begin{array}{l}\text { USAID, ITU } \\
\text { CTO (Commonwealth } \\
\text { Telecommunications } \\
\text { Organization) }\end{array}$ \\
\hline 1998 & $\begin{array}{l}\text { Regulatel } \\
\text { (Foro Latinoamericano de Entes Reguladores de } \\
\text { Telecomunicaciones) }\end{array}$ & ITU \\
\hline 1999 & $\begin{array}{l}\text { SAFIR } \\
\text { (South Asia Forum for Infrastructure Regulation) } \\
\text { Energy }\end{array}$ & World Bank, PPIAF \\
\hline 2000 & $\begin{array}{l}\text { AFUR } \\
\text { (African Forum for Utility Regulators) }\end{array}$ & World Bank, PPIAF \\
\hline 2000 & $\begin{array}{l}\text { CEER } \\
\text { (Council of European Energy Regulators), EU }\end{array}$ & $\begin{array}{l}\text { European Commission } \\
\text { (meetings in } 1996 \text { and } \\
\text { 1998) }\end{array}$ \\
\hline 2000 & $\begin{array}{l}\text { ERRA } \\
\text { (Energy Regulators Regional Association), } \\
\text { central/eastern Europe and the newly independent } \\
\text { states--Energy }\end{array}$ & US AID and NARUC \\
\hline
\end{tabular}

\footnotetext{
${ }^{4}$ Since the focus here is on more organizations created by and for regulatory commissions, the list does not include OLADE, CITEL, ERGEG, and ERG—-though those organizations are discussed later.
} 


\begin{tabular}{|c|c|c|}
\hline Date & Organization & Seed Money \\
\hline 2001 & $\begin{array}{l}\text { ADERASA } \\
\text { (Association of Water and Sanitation Regulatory } \\
\text { Entities of the Americas) }\end{array}$ & World Bank, PPIAF \\
\hline 2002 & $\begin{array}{l}\text { OOCUR } \\
\text { (Organisation of Caribbean Utility Regulators) }\end{array}$ & USAID \\
\hline 2002 & $\begin{array}{l}\text { ERG } \\
\text { (European Regulators Group) for Electronic } \\
\text { Communications Networks and Services, } 2004\end{array}$ & European Commission \\
\hline 2003 & $\begin{array}{l}\text { ARICEA } \\
\text { (Association of Regulators for Information and } \\
\text { Communication Services of Eastern and Southern } \\
\text { Africa) with COMESA }\end{array}$ & USAID \\
\hline 2003 & $\begin{array}{l}\text { EAPIRF } \\
\text { (East Asia and Pacific Infrastructure Regulatory } \\
\text { Forum) }\end{array}$ & $\begin{array}{l}\text { World Bank Public } \\
\text { Private Infrastructure } \\
\text { Advisory Facility } \\
\text { (PPIAF). }\end{array}$ \\
\hline 2006 & $\begin{array}{l}\text { RERA } \\
\text { (Regional Electricity Regulators Association), } \\
\text { Southern Africa }\end{array}$ & $\begin{array}{l}\text { SADC (Southern African } \\
\text { Development } \\
\text { Community) }\end{array}$ \\
\hline
\end{tabular}

Other types of organizations populate the field of regional collaborative groups. The networks can be divided into global, regional, and national in character; these can be further characterized having informal (networks and voluntary associations) and formal (agencybased or ministerial) features. In addition, some formal organizations are treaty-based or embedded in the United Nations, International Telecommunications Union, European Union, Organization of American States or other larger institutions. Here, the focus is on voluntary participation in regional associations of regulatory agencies, though their activities (and outputs) often parallel those of other networks.

\section{Forces behind the Creation of Regional Regulatory Networks}

Sandler (2006) provides a comprehensive typology of factors affecting the supply of transnational and regional public goods (RPGs). ${ }^{6}$ RPGs (especially those associated with developing countries) involve a unique set of potential funding groups and beneficiaries. This section examines regional organizations producing and sharing knowledge about infrastructure regulation: physical links and the need for coordination, policy harmonization

\footnotetext{
${ }^{5}$ EAPIRF is currently supported by the World Bank and the Australian Government. (See www.eapirf.org for more information.)

${ }^{6}$ RPGs fall between national public goods (NPGs) and global public goods (GPG); each of which has features that can promote (and deter) the appropriate provision of the public good. For example, a NPG, like cleansing a local ecosystem, has costs and benefits that can be addressed at the national level (since there are no international spillovers). A GPG, like reducing emissions contributing to global warming, has costs and benefits that require a more comprehensive set of international institutional arrangements.
} 
within regions, sources of seed money for institution-building, and global vs. regional initiatives.

2.1 Physical Links and Coordination The integration and modernization of a region's infrastructure (including energy, telecommunications, water/sanitation, and transport sectors) are often promoted as essential for sustainable economic and social development. Strains on individual country's limited resources can partly be mitigated by the provision of infrastructure related RPGs. For instance, there are strong regional benefits from transnational networks of gas pipelines across neighboring countries: there are gains from trade between Argentina, which owns abundant natural gas deposits, and Chile which does not. Natural gas pipelines between countries can be regionally beneficial by providing cost effective and more reliable energy supply. (Estevadeordal, et. al.2004).

Complementing physical networks are the networks of regulators which facilitate the sharing of information and experience among organizations facing similar challenges. Collaboration across national boundaries can improve regulatory strategies for establishing credibility and legitimacy for new governmental agencies responsible for monitoring infrastructure suppliers and implementing public policy. Prior to the creation of separate regulatory agencies, these tasks tended to be performed in a nontransparent way by government ministries. The same ministries often were responsible for the state-owned enterprises providing infrastructure services. Splitting regulatory agencies off from ministries was supposed to insulate those implementing policy from daily political pressures. Thus, the "Washington Consensus" promoted the creation of autonomous regulatory commissions since they gave private investors greater confidence that key pricing decisions and investment targets would not be completely politicized. In addition, the existence of national agencies left jurisdictional gaps in addressing cross-country network issues (Binger, 2003), including pricing policies for electricity grids linking nations and radio spectrum allocation policies. However, since such issues can raise fundamental foreign policy issues, national ministries and formal treaties tend to be the main parties and mechanisms for negotiating agreements. National regulatory bodies generally serve in an advisory role in such situations, providing expertise regarding basic conditions in the industry.

2.2 Policy Harmonization within Regions The emergence of some regional regulatory networks has been stimulated by the need to close jurisdictional gaps by creating entities capable of coordinating national and regional actions and/or supplying advice to ministeriallevel entities. For instance, with the creation of the European Union (EU), there emerged a need to develop consistent rules (and regulatory institutions) that were appropriate for the region. Harmonization became the task for regional agencies. Eberlein and Grande (2005) point out that European infrastructure groups did not possess the formal powers and the institutional capacities to develop the appropriate rules to enforce compliance in member states. Regional regulatory networks filled part of this void by coordinating the regulatory activities of EU member-nations. Regional regulatory networks in the EU promote decentralization while facilitating uniform standards and agreements on broad policies. For example, the European Regulatory Group (ERG) benefited from European Commission's creation of a permanent secretariat for the group. Coen and Thatcher (2006) point out that although the initial motivation behind the network was the creation of European guiding 
principles, ERG has evolved in such a way that it now primarily develops guidelines for implementing EU directives. The ERG illustrates how networks are often stimulated by regional developments.

2.3 External Seed Money for Institution-Building In some cases, outside funding served as a key catalyst for establishing the organization-funding the creation of Web pages, travel for meetings, and organizational support. Without external seed money, many of the regional associations in Table 1 probably would have been established but would have had weaker institutional support. The funding patterns are particularly interesting as multilateral and bilateral donor organizations provide support in areas of strategic interest. Of course, without local recognition of gains, the organizations would have been doomed to failure. Clearly, leaders of "infant" and "youthful” regulatory commissions saw benefits from more formal forums for information-sharing.

In the last decade, financial support for the creation of regional regulatory networks in developing countries has come from the World Bank, regional development banks, and national development aid agencies. Travel, meetings, secretariats, and working groups require funds. The Private-Public Infrastructure Advisory Facility (PPIAF, a multidonor technical assistance entity that works with the World Bank) has supported a number of regional initiatives. PPIAF provided the South Asian Forum for Infrastructure Regulation (SAFIR) with about $\$ 400,000$ in 1999. Starting in 2002, PPIAF provided $\$ 544,500$ to strengthen the Association of Water and Sanitation Regulatory Entities of the Americas (ADERASA). PPIAF funds also stimulated the creation of the African Forum for Utility Regulators (AFUR); along with co-funders it has provided over \$1 million to AFUR over the past seven years. The same catalytic role was played by PPIAF and AusAid (Australia's Overseas Aid Program) in the creation of the East Asia and Pacific Infrastructure Regulatory Forum (EAPIRF); the budget of \$2.5 million for 2006-2008 promotes information exchange (via Web pages and Annual Meetings) and capacity building in the region. The United States Agency for International Development (US AID) has provided several millions of dollars to assist in the creation of Central Europe and Central Asia's Energy Regulators Regional Association (ERRA), with the National Association of Regulatory Utility Commissioners (NARUC) providing the institutional expertise. NARUC support for this twenty-two nation network has included training programs, meetings, exchanges, web site development, and a number of agency partnerships/twinning arrangements (Voll and Skootsky, 2004). ${ }^{7}$ As some ERRA-member nations have joined the EU, their continuing participation has become more complicated.

2.4 Global vs. Regional Interests Some global institutions promote networking. The International Telecommunications Union (ITU, now with a UN affiliation) emerged to address specific industry issues and has branched out into other areas. Telegraph and transoceanic messaging served as the catalyst for the ITU's creation in 1865 . New technologies, the shift to privatization, and market liberalization have brought a new set of

\footnotetext{
${ }^{7}$ Voll and Skootsky (2004) report that from 1999-2004, in-kind (often bilateral) contributions from state commissions amounted to $\$ 750,000$. Their evaluation of ERRA's programs is the most comprehensive to date of a regional regulatory network. PPIAF has funded a similar review for infrastructure capacity building in Africa.
} 
issues to the fore, so a revived ITU serves as a forum for governments to reach consensus on policy harmonization. Some of the regional networks in telecommunications have their start in the ITU.

Other infrastructure sectors, like energy and water, have global organizations that serve similar roles. The International Energy Agency (IEA) has 26 member nations: collecting statistics, providing forums for the discussion of regional and global issues, and publishing reports on various topics. Established in 1973 in the wake of the first oil price run-ups, the IEA is comprised of developed (energy-consuming) countries. However, developing countries also participate in IEA events. The World Water Council (WWC, created in 1996) organizes the World Water Forum every four years. This multi-stakeholder organization brings together the diverse groups interested in a variety of topics including water supply, water quality, sanitation, and irrigation. Representing a coalition of many water organizations (including the American Water Works Association-AWWA), the WWC provides a platform for international dialogues. Although none of these international institutions focus on sector regulatory issues, agencies send professionals to speak at and participate in organization sponsored events-which facilitates networking across countries.

These international organizations view themselves as providing public goods, including technical knowledge, regulatory best practice, the promotion of professional training, and standards setting as well as the harmonization of national regulatory rules. Such networks influence decision making in global infrastructure, creating arenas for countries to explore common issues more effectively.

While seed money has come from external sources, national regulators have not been passive; they have sought funds for providing RPGs. In addition, they have obtained support/approval from national governments to participate in regional activities. Sector regulators may see gaps in the approaches or priorities of global institutions (like the ITU, IEA-International Energy Agency, or IWA-International Water Association)) to solving problems. At the global level, in some conferences, presentations are heavy on rhetoric and platitudes; furthermore, global infrastructure organizations often do not provide funds for implementing “commitments.” Also, in some international arenas, there may be a gap in negotiating capacities between industrial and developing countries. Sometimes the gap may serve as a stimulus for the creation of regional cross-country networks that can provide equal participation of all representatives who are engaged in addressing issues unique to particular regions.

Table 2 depicts the pattern of regulatory networks providing RPGs across regions of the world and across infrastructure sectors. The regional networks are in bold, while several inter-governmental organizations (e.g., Organización Latinoamericana de Energía - OLADE and Comisión Interamericana de Telecomunicaciones - CITEL) are included in the table as well; the roles of inter-country ministerial organizations are discussed in a later section. For completeness, those organizations that focus on issues of concern to infrastructure regulators 
are included in Table 2. In addition, several national regulatory commission associations that have played significant international roles are also included in the table. ${ }^{8}$

Table 2. Regulatory Organizations and Related Associations

\begin{tabular}{|c|c|c|c|c|c|c|c|c|}
\hline & Global & Africa & $\begin{array}{c}\text { Latin } \\
\text { America }\end{array}$ & $\begin{array}{c}\text { North } \\
\text { America }\end{array}$ & Caribbean & $\begin{array}{c}\text { Asia and } \\
\text { Pacific }\end{array}$ & Europe & $\begin{array}{c}\text { Island } \\
\text { Nations }\end{array}$ \\
\hline $\begin{array}{c}\text { All } \\
\text { Sectors }\end{array}$ & IFUR & AFUR & - & $\begin{array}{l}\text { CAMPUT } \\
\text { NARUC }\end{array}$ & OOCUR & $\begin{array}{c}\text { EAPIRF } \\
\text { SAFIR }\end{array}$ & - & ACCC \\
\hline Energy & IEA & RERA & $\begin{array}{l}\text { OLADE } \\
\text { ARIAE }\end{array}$ & & - & - & $\begin{array}{c}\text { CEER } \\
\text { ERGEG } \\
\text { ERRA } \\
\end{array}$ & - \\
\hline Telecom & ITU & $\begin{array}{c}\text { TRASA } \\
\text { ARICEA } \\
\text { WATRA }\end{array}$ & $\begin{array}{c}\text { CITEL } \\
\text { Regulatel }\end{array}$ & & ECTEL & SATRC & $\begin{array}{l}\text { IRG } \\
\text { ERG }\end{array}$ & - \\
\hline Water & $\begin{array}{l}\text { WWC } \\
\text { IWA }\end{array}$ & WUP & ADERASA & AWWA & - & SEAWUN & & - \\
\hline
\end{tabular}

Almost all the regions of the world now have regulatory forums of one type or another. In some regions, many national regulators are multi-sector-leading to the creation of entities that promote interactions across all sectors (AFUR, OOCUR, EAPIRF, and SAFIR). Sectorspecific regulatory networks tend to characterize some regions. For example, Latin America does not have a network of all regulators cutting across sectors, nor does Europe.

\section{Non-rivalry, Non-excludability, and Aggregation Technology}

Sandler (2006) shows how the provision of RPGs, including information, is influenced by three properties of publicness: non-rivalry of benefits, non-excludability of benefits and aggregation technology. Non-rivalry of benefits means that multiple individuals can consume the same good without diminishing its value to others who consume. For instance, research findings can be disseminated at no cost to users via the Internet without limiting the access of others. Non-excludability of non-payers exists when non-paying as well as paying individuals have equal access to a good. That is, potential consumers cannot be prevented (or excluded) from consuming the good. In the case of Internet access to data, the report may not involve rivalry in consumption (more for you means less for me) but the report and associated data can be password protected-leading to excludability.

3.1 Pure Public Goods A good that is both non-rival and non-excludable in benefits is considered to be a pure public good: the market will fail to provide the efficient level of such goods. If the good is non-rival and non-excludable across countries in a region, then the good

\footnotetext{
${ }^{8}$ The Brazilian Association of Regulatory Agencies (ABAR) is another association of state and national regulators that promotes information-sharing among agencies.
} 
is considered to be a pure RPG. Pure public goods, though uncommon, are difficult to provide because financing their provision is problematic: free-riders benefit from their production but do not contribute to ensuring that production costs are covered. Furthermore, establishing incentives for cost-minimization in production raises additional problems: collective action can be messy, reflecting personal egos, national rivalries, and interference by external funding agencies. In the case of a pure RPG, some financing could be provided by national agencies. In such cases, provision depends on the ability of the public sector to contribute funds for the provision of the good; nevertheless, the free-rider problem remains. Of course, without a market, valuations are communicated not through marginal outlays by beneficiaries but through statements at meetings. Individual nations may not contribute since collective financing ensures some provision, regardless of whether one country contributes or not. The existence of non-rivalry and non-excludability reduces the likelihood of the RPG's provision (without the infusion of external funds).

3.2 Impure Public Goods and Club Goods More commonly, RPGs will convey benefits that are either partially non-rival or partially excludable. If the bundle of RPGs has some excludability features, benefits can be withheld from non-payers, making the good an impure public good. Exclusion will encourage voluntary contributions and a fee can be charged for observed usage. A club good is excludable and partly rival. Users can form a club to provide the (partially rival) shared goods. The possibility of club goods increases the likelihood of successfully providing a RPG since it, too, allows some amount of excludability. RPGs that are club goods are typically provided within a structure where non-members are excluded (or have to pay fees to enjoy the benefits of the good), while members pay a relatively low usage fee (usually close to marginal congestion cost). Examples of RPGs that are club goods include training for professional staff and workshops, where a leader nation or organization markets the good.

The prospect of providing a RPG with some rival characteristic can promote efficiency, because rivalry in consumption allows market pricing to ration the good to those who value it the most. Access to the benefits of a rival or partly rival good can be exchanged for a per unit price. When the supply of the good is exhausted due to rivalry between consumers, supply shortages provide incentives via higher prices: leading to output expansion and marketclearing outcomes. Of course, in the case of some RPGs provided by regulatory networks, support from donor organizations and nations partly compensates for the small budgets (and lack of professional expertise) at newly-created national commissions. To promote the expansion of national infrastructure, donors have supported regulatory networks that promote capacity-building and information-sharing at new national commissions.

3.3 Aggregation Technology The third property of publicness, the aggregation technology, refers to the importance of supply side properties in influencing RPG provision (Holzinger, 2001). The aggregation (or production) technology will determine how individual contributions affect the total supply of the RPG. The supply of a RPG will therefore depend not just on the extent of non-rivalry and non-excludability of benefits, but on whether or not the contributions of nations or participants are additive and whether contributions can be substituted for one another. 
The aggregation technologies that appear to be most relevant in the context of infrastructure networks RPGs are weaker-link, weighted sum, threshold, and better-shot technologies. ${ }^{9}$ In the case of the weaker-link aggregator, the total level of the RPG will be influenced most by the smallest level of contribution, followed by the second smallest, then the third smallest and so on. Essentially the largest level of contribution plays the smallest role in determining the total supply of the RPG. With the weaker-link technology, shortcomings in the participation of one agent can be cushioned by the involvement of others: those with the smallest initial contributions are presumably the weak links that have the lowest willingness/ability to pay. For example, a unanimous pronouncement will depend heavily on the views of those with the least interest in the topic. Of course, repeated play can serve as a discipline on excessive recalcitrance, and log-rolling provides an incentive to cooperate since the outcome can be win-win over the course of several years.

With the weighted-sum aggregation technology, the total amount of the RPG supplied is a weighted sum of the contributions to the good. Such contributions need not be financial. In the case of regional networks of regulators, one nation may have laws that allow it to collect higher quality information from each utility. That nation's data may then serve as a template or model for other nations - giving its contributions greater weight than data from other nations. With this technology, individual agents' contributions are not homogeneous; as a result, differential impacts are present. How that affects incentives to contribute is unclear. Data-rich nations may not find substantial incremental benefits of obtaining data from other nations. On the other hand, the cost of providing data is low, unless variable definitions differ across countries. In such situations, the formats and definitions used by "dominant" data suppliers tend to be adopted by the group. There is evidence that countries standing to benefit the most from a public good are more inclined to contribute to its provision.

The threshold aggregator technology is where the benefits of the RPG are only realized after a certain level of the public good supply is reached. Output below this level is not valued by individual (potential) beneficiaries. For example, if data provided by members of the network are of very poor quality, the database will be relatively useless. Some basic level of confidence in the numbers is required to facilitate benchmarking and support other kinds of analyses. Thus, for data products, the network will attempt to set data collection standards: common definitions, auditing procedures, and validity checks.

The better-shot aggregator is a variation of the best-shot technology. Better-shot technology is the opposite of the weaker-link technology because with the better-shot technology, the total supply of the RPG depends mostly on the largest contribution, with the importance of each remaining level of contribution diminishing with its size. The better-shot technology is applicable to regulatory network RPGs where "best" contributions come in the form of model laws or well-documented rate reviews. So long as one country provides best-practice examples, the others benefit from the sharing of information.

\footnotetext{
${ }^{9}$ Hirshleifer (1983) deserves credit for developing the notion of aggregation technology, which he called a social composition function. Cornes (1993) and Cornes and Sandler (1996) first came up with the notion of weaker-link and better-shot public goods.
} 
Note that aggregation technologies are dynamic in nature: technologies are not stable; they change over time. Even if the structural form of the function remains the same, for instance in the case of the threshold aggregator, the parameters of the function might change as communication costs continue to fall. Further consideration of this issue would take us beyond the scope of the present paper, but clearly the Internet and video-conferencing change the way infrastructure agencies can interact across national boundaries. ${ }^{10}$

3.4 Products of Regulatory Networks The analysis of a pure public good suggests that if it is supplied privately (by the market), it will be provided in insufficient quantity. In the case of regulatory networks, the primary outputs (RPGs) are (1) events and meetings; (2) data for benchmarking; (3) public pronouncements; (4) materials for stakeholders, (5) capacitybuilding for professional staff; (6) best practice laws, procedures, and rules; (7) regulatory network news; and (8) technical studies. Table 3 characterizes these outputs as pure RPGs, impure RPGs, or club goods and in terms of their aggregation technology. The basis for the distinction between the types of RPGs is based on the extent to which their production satisfies the non-rivalry of benefits and the non-excludability of non-payers properties. The definition of the RPG and its characteristics help determine the corresponding aggregation technology.

Table 3. Characteristics of Regulatory Network Regional Public Goods

\begin{tabular}{llll}
\hline Pure RPG & $\begin{array}{l}\text { Impure RPG } \\
\text { (excludability) }\end{array}$ & $\begin{array}{l}\text { Club Good } \\
\text { (impure with some } \\
\text { rivalry of benefits) }\end{array}$ & $\begin{array}{l}\text { Aggregation } \\
\text { Technology }\end{array}$ \\
\hline & & Events and Meetings & Weighted-Sum \\
\hline & Benchmarking Data & Threshold \\
\hline $\begin{array}{l}\text { Public } \\
\text { Pronouncements }\end{array}$ & Stakeholder Material & $\begin{array}{l}\text { Capacity-Building/ } \\
\text { Training }\end{array}$ & Better-Shot \\
\hline & & Better-Shot \\
\hline $\begin{array}{l}\text { Best Practice Laws, } \\
\text { Procedures \& Rules }\end{array}$ & & & Summation \\
\hline Network & & Weighted-Sum \\
News & & &
\end{tabular}

(1) Events and meetings are club goods. Non-contributors can be excluded and congestion effects can arise to the extent that having a very large number of participants reduces candor and/or opportunities to raise questions. Such gatherings can be supplied on a commercial basis: the number of technical conferences available to potentially interested parties is vast. Nevertheless, an event sponsored and organized by a network of regulators fills a unique niche in the array of events available to regulatory professionals. The topics, speakers, and formats can be determined by leaders seeking information and fresh perspectives. In

${ }^{10}$ A colleague, Jose Tavara (Pontifica Universidad Catolica, Lima), identified the dynamic nature of aggregation technologies as an issue warranting further exploration. For example, the internet alters the cost of information-sharing and facilitates critical commentary. 
addition, such events can promote collegiality in the region. For example, as regional electricity grids become more important, the payoffs increase to harmonization of national regulatory policies and regulatory support of coordination among firms. Excludability is feasible: through registration criteria, attendance can be limited to official representatives of regulatory institutions.

In the case of the National Association of Regulated Utility Commissioners (NARUC) meetings in the U.S., some sessions are only open to commissioners or to commission staff, while other activities and presentations are available to all registrants. Meetings are a source of net revenue for NARUC. The possibility of exclusion from events and meetings on the basis of membership qualifies this product as a club good. In the case of regulatory networks, associations can practice price discrimination. Fees for some events, like dinners or plenary sessions for conferences, can be higher for non-members (such as managers of regulated firms) who value the opportunity to gauge regulatory attitudes. To limit perceptions of improper access to regulators, some meetings might be closed to outsiders-so the meetings provide opportunities to share more sensitive information and strategies across national boundaries. Contributions of participants to these meetings and events will differ depending on regional interests and objectives. The participants who are most eager to contribute are the ones who are most likely to benefit from a particular topic or format of an event. Outputs of an event that are most beneficial to one country or region may be less beneficial for some other region, sector, or country. The benefits of such meetings and events can therefore best be gauged by using the weighted-sum technology.

(2) Data for benchmarking consist of cross sectional data that are used for comparisonsover time and across utilities. For example, quantitative studies using stochastic frontier techniques or data envelopment analysis are becoming key elements for determining Xfactors for price cap regimes or network expansion targets. With information about what other utilities have been able to achieve with comparable inputs, the regulator is in a position to better establish targets, create incentives, and defend decisions. In addition to cost and productivity, service quality, network expansion, and prices can be compared across utilities and countries. Access to benchmarking data reduces the information asymmetries characterizing typical regulatory situations. This product is particularly important for developing nations where, historically, record-keeping has been weak. Regulators in a large nation can compare performance across suppliers, identifying strong and weak firms. For smaller nations with only one supplier of network services, data from neighboring nations facing similar geographic, topological, and resource constraints can be very helpful. Of course, national regulators can exclude others for accessing the information (an excludable public good), but that runs counter to transparency and citizen participation in the processreducing the legitimacy of the regulatory process. ERRA receives some funds by charging for access to benchmarking databases.

Developing templates for reports (and data definitions) does require collaboration or acceptance of formats developed by others. In this context then, data for benchmarking could more realistically be viewed as a pure public good. The non-excludability of benefits property of this good gives rise to potential supply problems, especially where data are difficult to disaggregate and where updating record-keeping (and standardizing definitions) 
may require significant effort. The usefulness of benchmarking data will therefore depend on the effective collaboration of enough countries within regions with sufficient data to make performance comparisons useful. Data below a certain threshold will be useless for comparison: benchmarking would be ineffective. ${ }^{11}$ In Africa, the World Bank sponsored the Water Utility Partnership (WUP, started in 1996) which represents a network of service providers created to promote the sharing of information and capacity-building. Since few African nations had separate water regulators for their state-owned enterprises, WUP filled a role in the initial development of benchmarking data. The Southeast Asia Water Utilities Network (SEAWUN) is another collaboration among service providers (founded in 2002 with support from the Asian Development Bank). Again, the focus is on improving sector performance through the creation of RPGs.

(3) Public pronouncements made by regional regulatory networks are unlikely to be highly controversial, given the weakest-link technology. Nevertheless, such statements represent shared views on important issues, identify objectives (if not overall priorities), and provide guidelines for strengthening regulatory procedures. Public pronouncements_are official statements, notices, or announcements that are recognized by authorities as providing principles that affect how regulators address issues. Public pronouncements include documents such as a network's mission statement. One role of public pronouncements is to make commitments to providing particular programs, support, and information. Public pronouncements are pure public goods because they are available to everyone and therefore are non-excludable in nature. The aggregation technology that is most appropriate to gauge the output of this public good is the weakest-link aggregator.

In 2004, for instance, the Association of Water and Sanitation Regulatory Entities of the Americas (ADERASA) Benchmarking Task Force met to agree on objectives and strategies, to discuss the basis of starting management indicators, and to establish the methodology and agenda for the initial stage of the project. In this setup, any member of the task force could potentially water down the quality of the objectives and strategies if they have an incentive to do so, because the benchmarking task force decision must involve the contributions of all its members. In group announcements of this nature, all the participants have to be in agreement. Some pronouncements reflect broad consensus about emerging issues (if not specific strategies for resolving those issues). ${ }^{12}$

\footnotetext{
${ }^{11}$ Benchmarking for water and sanitation utilities is promoted by the World Bank’s International Benchmarking Network for Water and Sanitation Utilities (IBNET) http://www.ib-net.org/. The site provides guidance on indicators, definitions, peer comparisons, and research methodologies. Due to potential privacy issues, identifiers are not shared. Collaborations in energy and telecommunications have similar "club" aspects-with even less public access to data. See the International Telecommunication Union Indicators Handbook http://www.itu.int/ITU-D/ict/publications/world/material/handbook.html.

12 For example, the Latin American telecommunications regulators' network (Regulatel) and Hispano-American Association of Research Centers and Companies of Telecommunication (AHCIET) co-sponsored a conference in July 2006 that led to a "Declaration on Convergence and Harmonization" in the digital arena. Such pronouncements can be vague, but the associated forums provide opportunities for exchanging ideas and sharing lessons.
} 
(4) Materials for stakeholders enable national regulatory commissions to educate and influence those affected by regulatory decisions. Establishing legitimacy for citizens and credibility for investors and ministries requires that agencies document procedures and methodologies. Such material represents another output that could be provided by external parties, including consultants funded by donor countries and multinational organizations. However, documents that are handed down by "outsiders" may not address the unique legal and other institutional features facing nations in a region. National regulators have less ownership of "hand-me-downs." Nevertheless, the Telecommunications Regulation Handbook $^{13}$ (2000), the Handbook for Evaluating Infrastructure Regulatory Systems (Brown, et al. 2006), and other volumes represent valuable starting points for national regulators. One could argue that this type of information tends to be a global public good since access to the information internationally is non-rival, and excluding non-payers from accessing the information is difficult. In recognition of the value of such material, the World Bank has been very active in funding the development of such resources. ${ }^{14}$

(5) Capacity-building for professional staff could be viewed as a private good with standard properties of rivalry in consumption and excludability (Rufin, 2004). Capacity-building technologies exhibit significant sunk costs and scale economies in the production of relevant materials and classes. Congestion effects might be of minor importance. Thus, while pure market mechanisms might yield relatively efficient outcomes for some types of classes for professionals, there is a case for cost-effective delivery of specialized training via cooperative programs across nations. For example, the Organization of Caribbean Utility Regulators (OOCUR) has put on advanced training courses for regulators in the region in collaboration with the Public Utility Research Center (PURC). The Energy Regulators Regional Association (ERRA) has developed links with (Hungary's Central European University (Regional Center for Energy Policy Research) to assist with training. The African Forum for Utility Regulators (AFUR) has worked with the University of Cape Town's Graduate School of Business Management Program in Infrastructure Reform and Regulation for developing and delivering training. In South America, the Universidad Argentina de la Empresa (UADE) offers a post-graduate program in regulation; UADE collaborates with regulators in the region; in addition, the Universidad Austral (Buenos Aires) offers a postgraduate course in regulatory legislation. ADERASA, in collaboration with UADE, is developing an E-learning Program in Economic Regulation, available not only for its own members but for all stakeholders, including regulators for other sectors and utility staff (www.campusvirtual.aderasa.org). Similarly, the Florence School of Regulation (with EU funding) has responded to training demands within the EU. Universities play an important role in this area, given their teaching capabilities and interest in translating principles into practice. ${ }^{15}$ In addition, consulting firms provide training and certification programs.

\footnotetext{
${ }^{13}$ The Information for Development Program http://www.infodev.org/ has published its Telecommunications Regulation Handbook (Intven and McCarthy, 2000) in six languages, hard copy and online.

${ }^{14}$ In addition to items noted in the previous footnote, the World Bank has manuals on price controls (Green and Pardina, 1999), infrastructure efficiency measurement (Coelli, et al. 2003), and other topics. In addition, the World Bank funded the Body of Knowledge on Utility Regulation http://www.regulationbodyofknowledge.org/.

${ }^{15}$ For example over the past decade, the University of Florida's Public Utility Research Center has delivered the PURC/World Bank International Training Program on Utility Regulation and Strategy to over 1,800 participants from 132 nations. See www.purc.ufl.edu.
} 
One potential role of regulator networks is to share information about the cost effectiveness of different programs and the quality of support materials. Partial exclusion encourages contributions (fee payment): in some instances, members of particular groups may benefit from the program at reduced cost, thereby increasing the likelihood that a regional training program will be successfully provided. Such a RPG can be viewed from the perspective of the better-shot aggregation technology. The total amount and the quality of training provided via regional networks are largely dependent on the trainer's effectiveness and the ability of network representatives to identify regional needs. Other determinants of quality are the contributions of the participants themselves. Lack of preparation on the part of participants can water down the value of a training session, but a poor quality leader/trainer can significantly lower the overall quality and usefulness of the program (suggesting that a weaker-link aggregator is also possible).

(6) Best practice laws, procedures, and rules that address institutional and policy issues on a regional or global level are useful to particular regions and countries depending mainly on how valuable or applicable general solutions can fit specific regional situations. ${ }^{16}$ Current responsibilities of regulatory institutions involve a set of tasks ranging from awarding licenses or concessions, administering rules included in licenses such as tariff levels and adjustments, resolving disputes among the different stakeholders (especially incumbents and entrants-in terms of interconnections and access to bottleneck facilities), monitoring firms' compliance with regulatory guidelines, and prosecuting and penalizing firms for noncompliance. The value of model laws will depend on how well they can be tailored to fit national contexts. The relevance and applicability of a model law determine the value of the output, but the use of less compatible information with particular institutional features could also contribute valuable information or guidance that helps to form the basis for action in accordance with the better-shot aggregation technology. For instance, information on how particular nations calculate rates for interconnection of telephone networks does not consider unique issues relating to the availability (and disaggregation) of historical (and forward looking) data which reduces the benefits of "model” procedures related to cost-based pricing. However, such information on a nation's experience can contribute conceptual frameworks that could be tailored to be used in deriving interconnection prices in another nation.

(7) Requlatory network news represents another product that is similar to events and training. Recent developments can be distilled and disseminated across countries. Professionals gain experience by contributing summaries of national developments-helping counterparts in other nations understand the implications of new rulings. Although information on new books, videos, and other educational material can be supplied competitively, regulator networks can screen, evaluate, synthesize, and promote the use of different types of material. Such evaluations are basically public goods-where the information might be shared informally (excludability possible) or through open Web sites.

(8) Technical studies including lessons regarding impacts of different policies, are GPGs or RPGs, depending on the applicability of the lessons for particular regions or for all nations.

\footnotetext{
${ }^{16}$ Dolowitz and Marsh (2000) describe the processes for policy diffusion and lesson-sharing across nations. Stone (2004) outlines the role of international actors (and organizations) in these knowledge-transfer activities. The role of networks is given particular attention.
} 
Rufin (2004) identifies research as one of the valuable regional public goods in his review of infrastructure issues. Analysts provide technical studies that can assist regulators in reforming the design of regulatory institutions, processes, and incentives. Studies are often funded by (and sometimes conducted by) donor nations and international organizations. Studies prepared under research contracts or consulting projects are often made available on sponsoring organization Web sites. Since there is no general recipe for best practice regulation, studies that incorporate the national (legal) and other institutional constraints can lead to insights for regulatory commissions facing similar circumstances. Regional task forces also give professional staff at national commissions opportunities to gain valuable experience in specialized areas through technical meetings. Related public goods are in systems that improve access to the diverse studies. Google represents one search mechanism (requiring some familiarity of how organizations support research and/or serve as gatekeepers in the process); the PPIAF-funded resource www.regulationbodyofknowledge.org is another vehicle for locating relevant infrastructure studies.

Note that when new regulatory agencies were being created in the 1990s, expertise in utility regulation was limited, particularly in developing countries. Leaders saw the potential for substantial savings if information could be shared between countries and sectors, even where particular agencies were contracting out for expert advice (often funded by donor nations or multilateral organizations). In essence, regional regulatory networking facilitates cooperation among countries to deal with shortages of technical know-how.

Expert views often provided a basis for policy recommendations; the associated studies were made available to interested participants including network operators, suppliers, consumers, and producers. Consultation documents are required to be accessible through a variety of platforms including the Internet. This feature of studies (and associated public consultations) makes such reports pure public goods, since their consumption is non-rival and no interested party can be denied access. ${ }^{17}$ The weighted-sum aggregator may be appropriate for determining the supply of this public good. The number and quality of studies will depend on the level of interest of the various constituents. Participation will be motivated to a large extent by the beliefs regarding how the resultant policy recommendations would affect each individual party. Studies will be provided primarily by those who will be most affected. These inputs are therefore the most important, followed by inputs or contributions of participants who are more marginally affected. Agents with no potential benefit from the product will not participate. Studies prepared for other jurisdictions have the disadvantage of having a different context, but the advantage of providing fresh (and potentially neutral) approaches to conceptual and quantitative issues.

\footnotetext{
${ }^{17}$ The European Regulators Group for Electricity and Gas (ERGEG) requires that all consultations at the national, European, and international levels be appropriately publicized, and all updates must be posted on the network's Web site. Consultation is a public process that allows responses from all parties that are interested in the process of policy formation. See http://www.ergeg.org/ for more information on ERGEG's public consultation procedures.
} 


\section{Ministerial vs. Regulatory Networking}

Government ministries are generally described as developing public policy, with agencies given the task of implementing policy. A sharp division of labor between developing and implementing infrastructure policy is not possible, since implementation often involves creating detailed rules (such as service quality standards) that become micro-policy. The creation of autonomous regulatory commissions has often been in response to pressure from international organizations. Operating companies (state-owned enterprises that sometimes were to be privatized) were split off from sector ministries. Private investors preferred to see a specialized regulatory entity that was insulated from day-to-day political pressures. So the new regulatory commissions were created to provide continuity in policy-implementation, greater transparency, and opportunities for public participation in the process. Once nations created agencies, the new sector regulators sought arenas for sharing information with neighboring countries - the beginning of inter-country collaboration to create RPGs.

Another vehicle for inter-country collaboration over infrastructure issues involves more formal organizations, often based on international treaties. ${ }^{18}$ Participants tend to consist of representatives of ministries responsible for particular sectors. In the case of energy in Latin America, an inter-country ministerial group was established over three decades ago. The Organización Latinoamericana de Energía (OLADE, Latin American energy organizations) had its origin in 1973, at the beginning of the energy crisis. Since then, it has served as a forum for discussing the development of energy resources in Latin America and the Caribbean. Energy ministers meet annually to share information. The United States is not a member. The networking organization for energy regulators in the region is the LatinAmerican Association of Regulatory Agencies for Energy (Asociación Iberoamericana de Entidades Reguladoras de la Energía, ARIAE). Created in 1997, the 19-member organization meets once each year to share knowledge related to regulation, human resource training, and R\&D in the energy sectors. Its products are excludable: the database is available to its members by accessing the Web site (password code secure).

The case of telecommunications policy in Latin America and the Caribbean is quite similar. CITEL and Regulatel represent different constituencies. The former was created in 1923 and is now a specialized unit within the Organization of American States (established in 1948), so it includes the United States. ${ }^{19}$ It has a ministerial basis-with an emphasis on regional policy issues: allocation of spectrum, development of technical standards, and analysis of the implications of new technologies. Regulatel, on the other hand, is an organization representing those implementing policy: the regulators. Established in 1998 following regional discussions regarding ITU reform, this network is more informal and focuses on issues facing regulators: dealing with powerful incumbent firms, designing interconnection regimes, comparing policies that promote universal service, and addressing issues of service

\footnotetext{
${ }^{18}$ The West African Telecommunications Regulators Assembly (WATRA, 2002) is a mixture of autonomous regulatory bodies and associated government ministries, receiving support from the Economic Community of West African States (ECOWAS). Such hybrids illustrate the difficulty of classifying regulatory networks.

${ }^{19}$ Feinberg (2006) compares the Summitry of the Americas, the Organization of American States (OAS), and the Inter-American Development Bank (IDB) as mechanisms for designing and implementing regional policies. The periodic Summits of the Americas generate directives involving "unfunded mandates" for the OAS and/or the IDB.
} 
quality. Both types of issues are important, and the resulting division of labor reflects the differential concerns of their constituencies. ${ }^{20}$

In Europe, the presence of powerful state-owned incumbent telecommunications firms was one factor leading to the creation of the Independent Regulators Group (IRG) in 1997. Formed by national regulatory authorities in Europe as a platform for discussing telecommunications issues, it explicitly excluded European Commission participation, perhaps since the latter (by its political nature) reflected the positions of other stakeholders, including finance ministries who might attempt to maximize the value of state-owned enterprises. In 2002, the European Commission established a parallel organization consisting of the national commission chairpersons and representatives of the EC: the European Regulators Group (ERG) for telecommunications. The ERG and the IRG currently share work programs, annual reports, and working groups. However, as the ERG Web site states, "As our ability to offer good advice to the commission will sometimes require us to take positions which are not identical to theirs, the existence of the IRG provides the national regulators with a useful forum.” Thus, the two organizations are closely linked but not identical. The ERG seems to be more of a hybrid collaborative network, involving regulators but having a European Commission-driven agenda. In 2004, the organization became the ERG for Electronic Communications Networks and Services, reflecting an emphasis on digital convergence and other developments in information technologies and products. Such hybrids suggest that no simple partitioning can be made regarding regulatory networks. ${ }^{21}$

\section{Regional Regulatory Institutions}

Another hybrid between ministerial and regulatory roles arises when infrastructure commissions are regional in nature. Because issues of national sovereignty arise when responsibilities are delegated to supra-national (regional) organizations, the number of transnational infrastructure regulatory commissions is relatively small. Furthermore, even when the entity has treaty-based authority, it often only makes recommendations to national authorities. Nevertheless, the recommendations have a legitimacy that national-sponsored proposals would not have because they are the result of a consensus that transcends national boundaries. For example, the Eastern Caribbean Telecommunications Authority (ECTEL) is a regional telecommunications advisory body for its member countries. ECTEL's responsibilities include the creation of a coordinated approach to telecoms regulation, and the promotion of fair competition in telecommunications service within its member countries. ECTEL advises governments on regional policy, types of telecommunications services, licensing, fees, pricing, and the management of the Universal Service Fund.

\footnotetext{
${ }^{20}$ Regulatel’s quarterly electronic newsletter (L@tin.tel) illustrates the ways that associations promote professionalism within commissions and the exchange of ideas across nations.

${ }^{21}$ A similar EU development occurred in energy. The European Commission issued market directives in 1996 and 1998. The EC then created the European Electricity Forum (Florence) and the European Gas Forum (Madrid) to promote the creation of a single market in the region. Ten national regulatory authorities established CEER in 2000. In late 2003, the EC created the European Regulators Group for Electricity and Gas (ERGEG) to "advise and assist the commission in consolidating the internal energy market." More stakeholders participate in this organization, with CEER collaborating with ERGEG.
} 
With the formation of international electricity grids, similar functions are beginning to be assigned to transnational regulatory agencies. The Economic Community of West African States (ECOWAS) secretariat is developing an agency that would assist in the regulation of transmission in the region. As in the case of ECTEL, issues of control (voting power) and authority (final decision or recommendations) will arise as national interests come into conflict. However, infrastructure development is not a zero-sum game: the gains to coordination can be substantial. The presence of network externalities-increased benefits with more members-makes the creation of physical networks (and RPG oversight agencies) a positive sum game up to the point at which all relevant members are included. The sequencing of investments, pricing of services, and incentives for good performance have implications across national boundaries, resulting in the creation of regional organizations. Similar groups have formed in South Asia, Central America, Southern Africa, and other regions.

\section{Concluding Observations}

The pace and pattern of newly created regional regulatory networks is consistent with their role in the production of RPG like events, information, and studies. These regional associations address concerns that are common to a particular region of the world. The World Bank explored the creation of a global regulatory forum: International Forum for Utility Regulation (IFUR), but the payoff to regional collaboration seemed to be higher than global cooperation. Very high level forums create opportunities for leaders from around the world to gather-but for newly formed commissions, working together in regions has lower costs and provides opportunities for greater participation by those with technical skills. The "lifeexpectancy" of a typical commissioner might be less than four years; professional staff can benefit from capacity-building and the sharing of experiences. Thus, regional networks are able to balance clout of regulatory leaders with the continuity of personnel. Furthermore, universities and consulting firms have played important roles in the dissemination of best practice across agencies and within regions-generally with the support of multilateral organizations or national donors. The characteristics of products (non-rivalry of benefits, non-excludability of non-payers, and the aggregation technology) have influenced the creation of these new international networks.

Establishing a research agenda is idiosyncratic, and thus problematic; however, the following questions might serve as starting points:

(1) What are the motives of the founding leaders of regional networks? The self-interest of networking bureaucrats warrants greater attention. Are those officials who are most active in regional networking seeking greater visibility? Given the tendency for relatively short terms of sector commissioners, do the working professionals at the agencies provide initiative and continuity or are the regulatory leaders the ones most committed to networking, given their interest in gaining information quickly so they can be effective during their short tenures? Of related interest is the role of outsiders (academics, consulting firms, and operating companies) in the evolution of these networks. 
(2) What are the optimal funding sources and mechanisms for regulatory networks? The case for further funding depends on incremental benefits exceeding incremental costs. Given the importance of stable, predictable, and transparent regulatory systems for infrastructure investment, performance improvements in just a few nations would justify the investments in regional data exchanges and sharing best practice techniques. However, that begs the question of whether the World Bank, regional development banks, or national aid agencies are best suited for funding and monitoring regional networks. One advantage of having multiple centers of initiative is that approaches suitable for particular regions will be developed-ultimately leading to transfer of best practice across networks. Whether some super-network of networks is needed is another issue worthy of investigation.

(3) What are the ultimate objectives of those providing seed money for these new organizations? The motivations behind funding organizations raise some interesting and important issues. While the networks may be producing regional public goods, the intentions of the actors involved in funding and advising the networks probably go beyond the "efficient supply of RPGs." For example, one likely objective for the World Bank's and USAID's early support for regulatory networks was improving the investment climate for private participation in infrastructure-which certainly can contribute to growth, but involved tilting multilateral and other funding away from state-owned enterprises.

(4) Does embedding these networking organizations within larger institutions improve their performance? Having an international umbrella organization (UN, EU, or OAS) might provide a funding source and expand the network's influence. Alternatively, the associated bureaucracy might lead to less innovative activities by the organization. Another model is having sector umbrella organizations like the International Telecommunications Union, International Energy Agency, and World Water Council take initiative for supporting regional regulatory networks. Feinberg (2006) begins to explore these types of issues, but more needs to be done.

(5) Is there an optimal region (or number) for networking? It is unlikely that there is a unique (and simple) partitioning of nations, given cultural heterogeneity in some regions (West Africa), different political traditions and stages of development, and degree of shared interests (or tensions). Nevertheless, it is worthwhile to consider whether particular circumstances are especially conducive to productive networking activities.

(6) What are the impacts of networking? A major area for future research involves determining whether the benefits (in improved national regulations and enhanced sector performance) have justified the investments in these new institutions to date. If the payoffs have been high, the World Bank and the regional development banks should consider devoting more resources to networking organizations that strengthen capacity at national regulatory commissions. 
These questions will require much more detailed analyses of case studies, including interviews with or surveys of those most affected by these new networking organizations: national commissioners and professional staff. Good infrastructure regulation has an indirect demonstration effect within each nation, illustrating how transparency, citizen participation, and staff professionalism promote legitimacy and public confidence. In addition, there is a direct effect on infrastructure: the promotion of network expansion, cost containment, and improved service quality. If a few nations have benefited from the outputs of regulatory networks, the initial seed money has been worth it. The next question is how to make such organizations more effective in improving infrastructure performance that contributes to economic and social development.

\section{References}

Binger, Albert (2003). "Global and Potential Mechanisms for Financing Availability,” Committee for Development Policy Meeting, April 7-11: 1-39.

Brown, Ashley C., Jon Stern, Bernard Tenenbaum and Defne Gencer (2006). Handbook for Evaluating Infrastructure Regulatory Systems, Washington, D.C.: World Bank. xx-397.

Coelli, Tim, Antonio Estache, Sergio Perelman, and Lourdes Trujillo (2003). A Primer on Efficiency Measurement for Utilities and Transport Regulators, The World Bank, Washington D.C. xii-134.

Coen, David and Mark Thatcher (2006). "After Delegation: The Evolution of European Networks of Regulatory Agencies,” ECPR Regulation Conference, Bath University, September 8-10: 1-21.

Cornes, Richard (1993). "Dyke Maintenance and Other Stories: Some Neglected Types of Public Goods,” Quarterly Journal of Economics, 108 (1), 259-271.

and Todd Sandler (1996). The Theory of Externalities, Public Goods, and Club Goods, $2^{\text {nd }}$ Edition (Cambridge: Cambridge University Press), 1-612.

Dolowitz, David P. and David Marsh (2000). "Learning from Abroad: The Role of Policy Transfer in Contemporary Policy-Making," Governance: An International Journal of Policy and Administration, Vol. 13, No. 1, January, 5-24.

Eberlein, Burkard and Edgar Grande (2005). "Beyond Delegation: Transnational regulatory regimes and the EU regulatory state,” Journal of European Public Policy, 12:1, February, 89-112.

Estevadeordal, Antoni, Brian Frantz and Tam Robert Nguyen, eds. (2004). Regional Public Goods: From Theory to Practice, Inter-American Development Bank and Asian Development Bank. 
Feinberg, Richard E. (2006). "Presidential Mandates and Ministerial Institutions: Summitry of the Americas, the Organization of American States (OAS) and the Inter-American Development Bank (IDB),” Review of International Organizations, 1: 69-94.

Green, Richard and Martin Rodriguez Pardina (1999). Resetting Price Controls for Privatized Utilities: A Manual for Regulators, The World Bank, Washington D.C., vii-109.

Hirshleifer, Jack (1983). "From Weakest-link to Best Shot: The Voluntary Provision of Public Goods,” Public Choice, 41 (3), 371-386.

Holzinger, Katharina (2001). “Aggregation Technology of Common Goods and its Strategic Consequences: Global Warming, Biodiversity, and Siting Conflicts,” European Journal of Political Research, 40: 117-38.

Intven, Hank and McCarthy Tétrault (2000). Telecommunications Regulation Handbook, Module 1. Overview of Telecommunications Regulation, The World Bank, Washington D.C.

Jordana, Jacint and David Levi-Faur (2005). "The Diffusion of Regulatory Capitalism in Latin America: Sector and National Channels in the Making of a New Order,” Annals of the American Academy of Political and Social Science (March), 102-122.

Kessides, Ionnis N. (2004). Reforming Infrastructure: Privatization, Regulation, and Competition, World Bank and Oxford University Press, xv-306.

Nogueira, Roberto Martinez (2004). "Regional Public Goods, Governance and Capacity Building,” in Estevadeoral et. al. 275-292.

Rufin, Carlos (2004). “Regional Public Goods and Infrastructure,” in Estevadeordal et. al., 181-202.

Sandler, Todd (2006). “Regional Public Goods and International Organizations,” Review of International Organizations,” 1: 5-25.

Slaughter, Anne-Marie (2000). "Governing the global economy through government networks" in The Role of Law in International Politics. Essays in International Relations and International Law, ed. M Byers, Oxford/New York: Oxford Univ. Press, 9:177-205.

(2004). "Disaggregated Sovereignty: Towards the Public Accountability of Global Government Networks,” Government and Opposition, 159-190.

Stone, Diane (2004). “Transfer Agents and Global Networks in the ‘Transnationalization’ of Policy,” Journal of European Public Policy, 11:3 (June): 545-566.

Voll, Sarah and Erin Skootsky (2004). “Evaluation of the NARUC Regional Energy Regulatory Program for Central/Eastern Europe and Eurasia and the Development of the Energy Regulators Regional Association.” NARUC, September. 1-73.

www.naruc.org/associations/1773/files/erraeval1104.pdf . 